\title{
Pedagogical challenges in teaching anatomy on a problem-based learning curriculum
}

\author{
Marcus Vinicius Jardini Barbosa ${ }^{1}$ (D), Angélica Marchini de Souza Jardini Barbosa² (D), \\ Sinésio Grace Duarte ${ }^{3}$ iD \\ ${ }^{1}$ Morphofunctional Laboratory, School of Medicine, University of Franca, Sao Paolo, Brazil \\ ${ }^{2}$ Operatory Technique Laboratory, School of Medicine, University of Franca, Sao Paolo, Brazil \\ ${ }^{3}$ General Coordination, School of Medicine, University of Franca, Sao Paolo, Brazil
}

\begin{abstract}
Objectives: This study aims to present the experience with several pedagogical tools in a morphofunctional laboratory of a school of medicine in Brazil.

Methods: Pedagogical strategies were divided into four categories; support materials, represented by a daily script, in accordance with tutorial sessions; practical activities when professors encouraged the students by an explanation about its content and the objectives to be achieved along the class; complementary (extra) activities with specific script and practice; optional activities represented by consulting periods, visit to anatomical exhibitions, and international courses.

Results: Activity scripts (Category 1) allowed students to previous study and to obtain an overview about the lab activities. Practical activities (Category 2) stimulated communication skills and teamwork as well as allowed students to ask questions and doubts. Complementary practices (Category 3) helped students to improve their knowledge based on the correlation between the contents from a new perspective. The optional activities (Category 4) were seasonally offered and showed an opportunity to practice the knowledge in a different reality.
\end{abstract}

Conclusion: The portfolio of activities for teaching anatomy in active teaching-learning methodology was quite variable and contemplated important aspects involved in the whole teaching-learning process.

Keywords: anatomy; graduate education; medical education; problem-based learning

Anatomy 2020;14(2):117-122 @2020 Turkish Society of Anatomy and Clinical Anatomy (TSACA)

\section{Introduction}

Implementation of new curricular guidelines for medical schools in Brazil brought many challenges in the development of the medical curriculum. Since the previous curriculum was traditionally fragmented in disciplines and cycles, the new curriculum was developed to be integrated by the construction of thematic modules including basic and specific disciplines. These contents will depend on the complexity of the stage along the course, according to the Miller's pyramid. ${ }^{[1]}$ New medical courses are "born" within these guidelines and older courses have the great challenge to adapt itself to this new reality, breaking paradigms. In this new curriculum, central agent of the teaching-learning process is the student and the professor become a passive agent; a facilitator of the whole process. ${ }^{[2]}$
These new guidelines increased the hours of boarding school and, consequently, it was necessary to restructure other areas of the course due to the reduction of their workload. ${ }^{[3]}$ These needs arise in order to build an integrated curriculum, whose content should contemplate the most important points that an egress should have for his professional life.

Anatomy has been traditionally taught in wet laboratories (with cadavers and dissections), in a "fragmented way" of the content of other basic areas, due to its extensive content. ${ }^{[4]}$ The implementation of integrated curriculum and the application of active teaching-learning methodologies, such as Problem Based Learning (PBL), brought the challenge to integrate the teaching anatomy with teaching other basic areas together. In this way, a new kind of labo- 
ratory came up - the morphofunctional dry lab. So, development of different pedagogical tools was necessary, due its new context, and also because of the scarcity of cadaveric material..$^{[5]}$

In addition to the changes in teaching-learning paradigms, technological advances must be considered as the same as the different approaches to work with the "digital natives" students, whose way of learning is completely different from previous generations. It will require from professors a new dynamic way during classes, mainly regarding the way of how this knowledge should be transmitted. ${ }^{[6]}$ This conception fits into one of the aspects of the called "meaningful learning", in which professors must have to give real meanings to what they will teach, in order to capture the whole student's attention, maximizing the teaching-learning process. ${ }^{[3]}$

Therefore, it is extremely important to evaluate and understand the main aspects involved in the current context of teaching and learning, especially in the use of active methodologies, so that, at the end of the process, the egresses may have all of the skills and competences required in their professional field with a critical and reflexive attitude. ${ }^{[6]}$ The objective of the study was to describe the experience in the use of several teachinglearning tools in a morphofunctional laboratory of a new school of medicine in Brazil.

\section{Materials and Methods}

The study was conducted in accordance with Helsinki guidelines. This was a descriptive study that describes the experience in teaching anatomy using different pedagogical strategies and tools whose were developed and applied in the morphofunctional laboratory. This was based on previous literature, adapted and improved to the local reality. These tools had always been used in addition to textbooks, anatomical atlases (printed or digital), softwares and electronic addresses on the web.

These strategies were divided into four categories:

- Category 1 (support materials for activities): The main tool was the daily activity scripts. These scripts were detailed and elaborated based on the content that was previous discussed in the tutorial sessions. It was divided in two parts: learning objectives and organs/structures to be observed (Figure 1). The script was previously available to the student, in order to allow them to know the content and the objectives to be achieved, enabling a better discussion during the lab and, consequently, a better comprehension at the end.

- Category 2 (practical activities): The activities were developed in the morphofunctional laboratory.

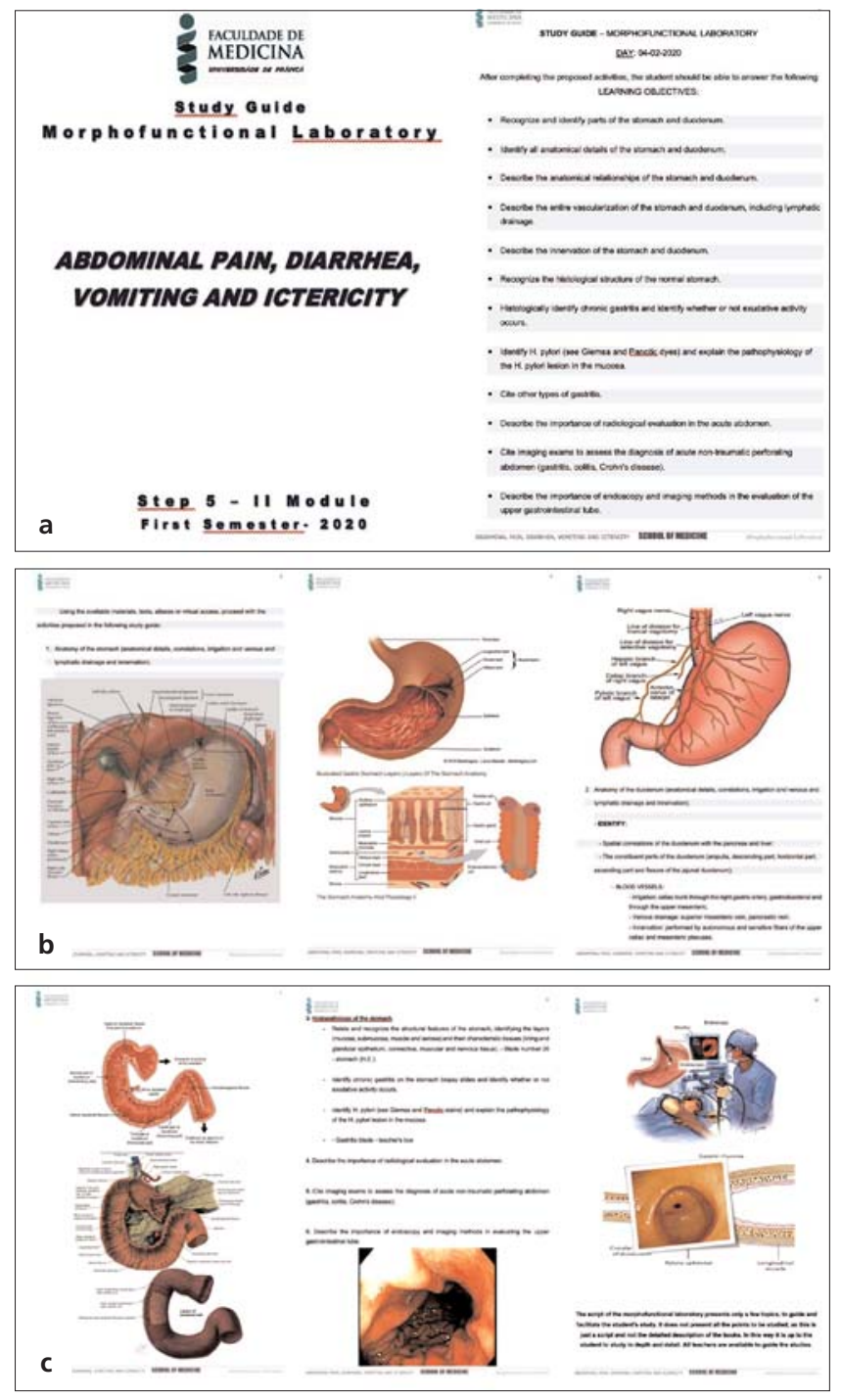

Figure 1. Sample of a general aspect of the activity guidebook. (a) Frontal cover and learning objectives; (b) Anatomy guide of the daily activity; (c) Histology and imaginology guide for correlation with anatomy.

Professors encouraged the students with a general explanation about the content of the script and the objectives to be reached. Students were stimulated to use anatomical models and charts, softwares and web pages, questionnaires (quiz sections), as well as textbooks and printed or digital atlas of anatomy to find answers and solve "problems". In order to make the activity more dynamic, students were divided into groups for presentation (seminars or skits) and discuss the daily objectives with their colleagues (Figure 2).

- Category 3 (complementary activities): The students developed their complementary activities at predetermined times guided by a specific script. The 
following tools were used: dissections of animal viscera (heart, liver, kidneys and lungs) with focus on comparative anatomy and physiology (Figure 3); study based on manipulation of parts or entire corpses in the wet anatomy lab. Depending on the content, students were encouraged to construct anatomical models with different materials such as plastic, styrofoam models, plaster, modeling mass and resin (Figure 4).

- Category 4 (optional activities): Optional activities were also offered and included such as weekly consulting with professors, visit to anatomical exhibitions (when available), and an annual international anatomy courses performed at the Miami Anatomical Research Center Institute (M.A.R.C. Institute) in the United States of America (Figure 5).

\section{Results}

All of the activities categorized above were systematized and included in the routine of the activities developed in the laboratory for all students from the first to the fourth year (about 400 students).

In Category 1 (support materials for activities), all the scripts referring to the thematic module were available previously to all students, at the institutional digital platform. This allowed students to have an overview of what would be addressed during the lab, and allowed them to come more prepared for the daily activities which included other disciplines, such as histology, imaginology, physiology, etc. This integration was important to give students a more holistic view of the anatomical structures as showed in the Figure 1. Students were stimulated to contribute with the improvement of the scripts through criticisms and suggestions.

Considering the practical activities (Category 2), it was observed that the introduction guided by the professors regarding the schedule of the daily activities allowed the students to ask questions and doubts, making clear some concerns that could be appear during their previous reading of the study guide. The different dynamics, such as the use of online quiz sections developed by the professors, made the students to integrate the content to be studied and help them to develop communication skills and teamwork, denying doubts and raising questions that were of general interest (Figure 2).

Complementary activities (Category 3 ) were directly correlated to the content of the morphofunctional laboratory and to the tutorial sessions. The general observation was that these activities helped students to improve their

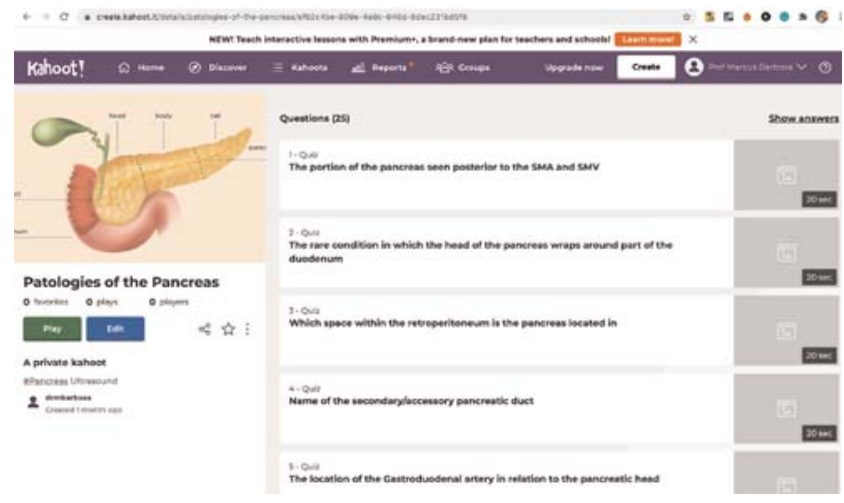

Figure 2. Overview of an online questionnaire activity to better explain the content.

knowledge based on the correlation between the contents from a new perspective, since the dynamics of the activity, as well as the practice in a non-ordinary environment, allowed a better concentration and perception allowing a holistic view of the whole content by the use of comparative anatomy (Figure 3) and as showed in the "construction" of anatomical models (Figure 4).

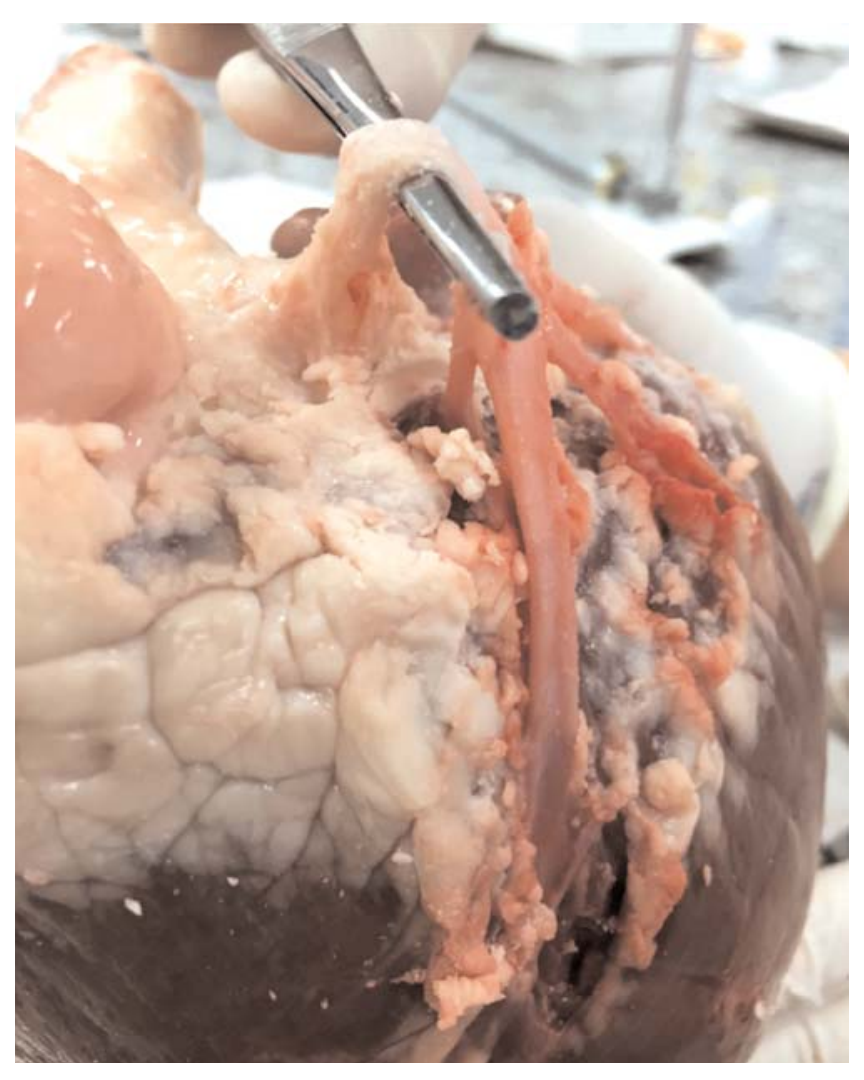

Figure 3. Dissection of animal viscera for comparative anatomy. In this figure, coronary arteries of a bovine heart are shown. 
The optional activities (Category 4) could have costs, and depended on exclusively the availability of the activity, or the student's will. Because they were optional activities, even at no cost, in many times the participation was low, especially in consultancies. However, when the cost of transportation was covered by the university, the visit to the anatomical exhibition "The Incredible Human Body" was attended by all students. The participation in the international anatomy course proved to be a very positive experience not only because of the opportunity to know an international institution, but also through contact with fresh frozen specimens and the practice of different language as well as culture (Figure 5).

\section{Discussion}

The technological evolution, the profile of the new generation and the real needs in the expanded understanding about health-disease process have brought questions to the traditional teaching-learning process in medical schools regarding the effectiveness on its new context. In this way, many other teaching-learn methodologies was developed and incorporated into the curriculum of the medical schools, mainly the new ones. ${ }^{[2]}$ These methodologies have broken paradigms by introducing new concepts based on the "inversion" of the teacher-student relationship. In this new context, students take the role of the active agent in the construction of their knowledge and the professor takes the role of facilitator of this process. ${ }^{[1]}$

In the new educational scenario, the transmission of knowledge through merely expositive classes or in traditional laboratory practices, has been questioned and others new teaching-learning tools have been introduced with the main objective of stimulating the student to "learn to learn". ${ }^{[7]}$ In this way, Mourthé Filho et al. ${ }^{[4]}$ emphasized that the educator must act effectively and apply innovative didactics to overcome new challenges in the teachinglearning process. Montes and Souza ${ }^{[3]}$ such as Costa et al..$^{[5]}$ have stated that the use of different tools in teaching anatomy facilitates learning and improves student performance. These aspects reinforce the need to introduce different teaching-learning tools as applied in the present study.

The previous availability of the activity scripts (Category 1) proved to be an important aspect that allowed the previous study of the content and, consequently, the better use of time with professors in the laboratory. The purpose of the scripts was to explain the content to the students specifying what they should know at the end of its execution. It was stablished that the lack of clarification about the goals to be achieved in a specific

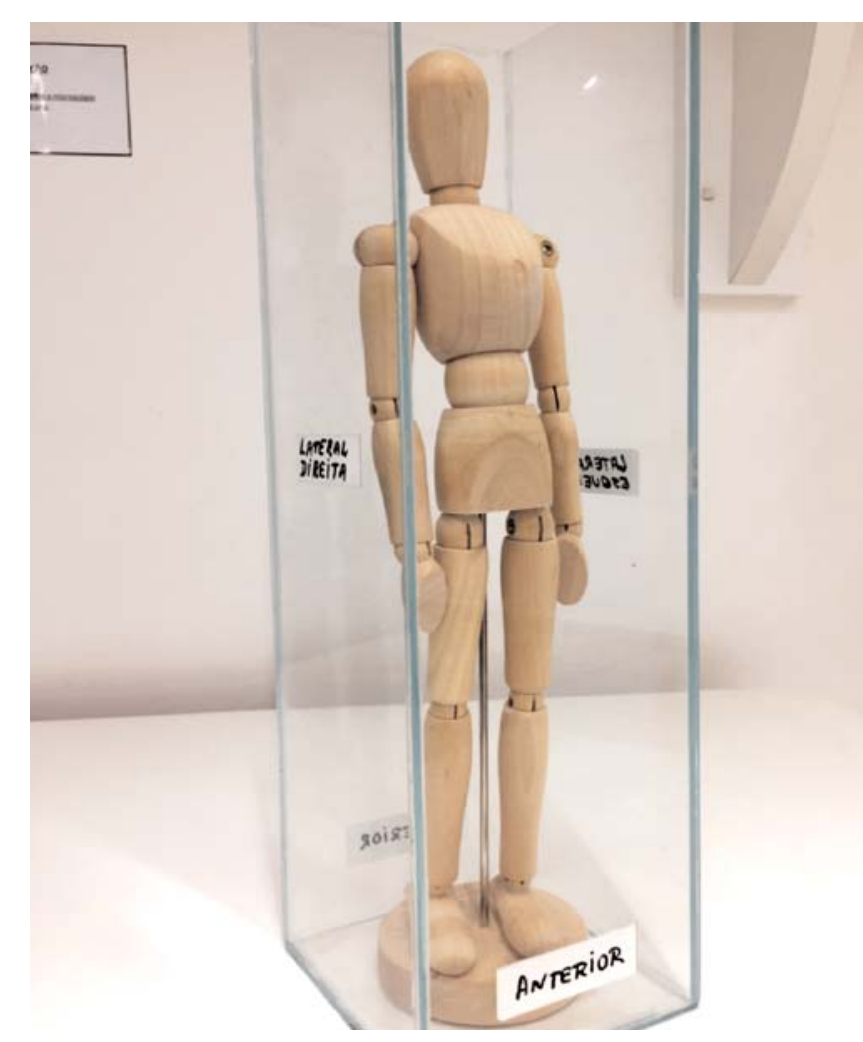

Figure 4. Model built with wood and glass to study anatomical planes and axes.

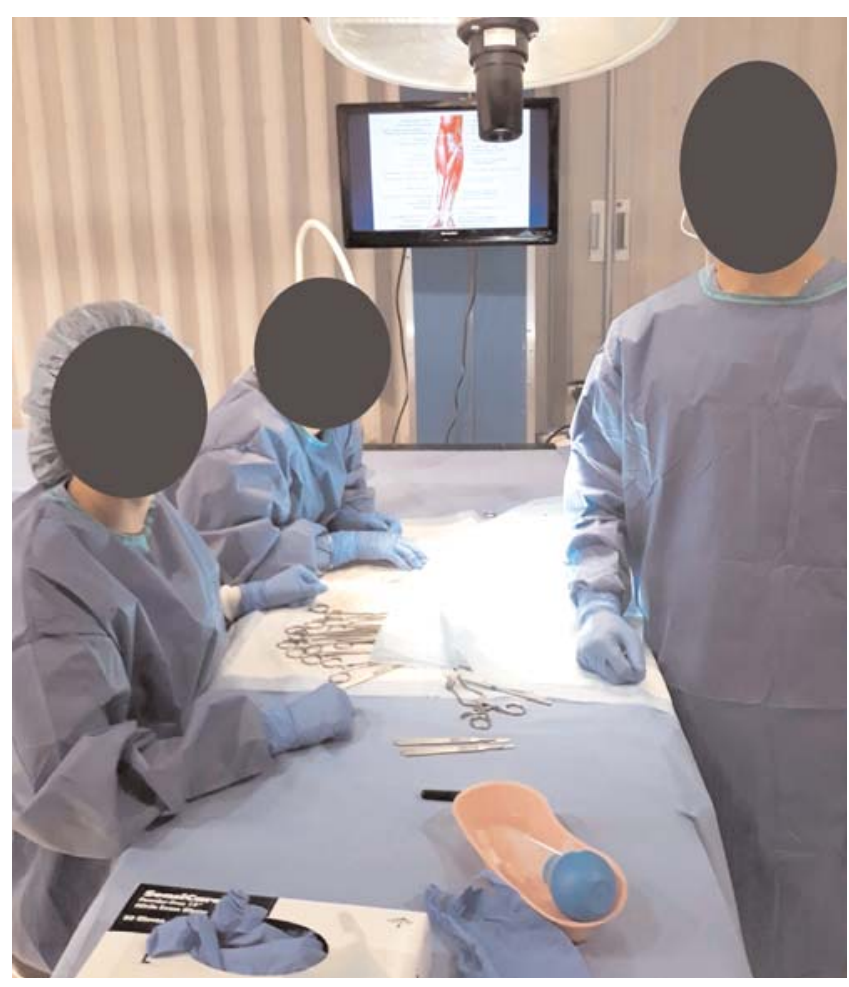

Figure 5. Advanced anatomy course at M.A.R.C. Institute - Miami, FL, USA. 
activity may result in a poor performance. ${ }^{[3,8]}$ Thus, the perception about the direction of the study and what should be known about that content, was relevant since it allowed the students to take their doubts and to complement their study begun in the tutorial sessions.

The different dynamics adopted during a lab session allow students to feel motivated and stimulated to learn more. In this way, every pedagogical resource that helps students in the construction of their knowledge must be used. ${ }^{[6]}$ The encouragement of students to work in groups, to organize seminars and presentations, may expose questions whose often not raised when they studied alone. ${ }^{[3]}$ The variety of pedagogical tools listed in Category 2, such as anatomical models, charts, short presentations, skits, team based learning, and seminars, made the activities more dynamic and interesting, since the perception was that the students felt involved and valued in the construction of their knowledge.

Considering Category 3, students had the opportunity to verify the texture and the whole aspect of a fresh organic structure (animal organs), besides practicing manual and dissecting skills, allowing the correlation with the human body through comparative anatomy. ${ }^{[9]}$

In Brazil, the main difficulty in obtaining corpses is due to ethical or legal limitations. Then, the practice of anatomical dissection is not a reality in many universities, especially the younger ones. However, the study of previously dissected parts of cadavers allow students to precisely locate different structures of the human body. This strategy was also used in the morphofunctional laboratory as a complementary activity. The construction of anatomical models was used at the end of the modular content. Students were divided into groups and were stimulated to build and present their work for the whole class. This pedagogical tool has proved to be effective, since it has the capability to develop attitudes, values, skills and, consequently, greater fixation of the content addressed. ${ }^{[10]}$

Among the activities without costs (Category 4), it is important to highlight the consulting periods. This strategy was individually and designed to provide an opportunity to ask questions, as well as for a specific guidance to plan the best way to study. However, there was a low participation of the students that may be explained by the excess of activities along the week in a medical course who applies the PBL in its entire curriculum. The art exhibition called "The Fantastic Human Body" had the cost of transportation covered by the university with great participation of the students. Despite being a seasonal activity, it was a good opportunity for students to know cadavers preserved by the plastination technique. ${ }^{[8]}$
The internationalization of undergraduate students is an increasingly growing reality that promotes the possibility of knowing other realities. It has been promoted the interest of students in order to expand their knowledge, creating a more critical and reflexive view of multiculturalism. ${ }^{[11,12]}$ International anatomy courses, performed at the M.A.R.C. Institute, were fully funded by the students. In this way, the participation has become limited mainly because its relatively high costs. However, students have described that the internationalization experience in a cadaver lab was extremely relevant in the context of teaching-learning process. Their main perception was that the manipulation of fresh cadaver, giving a more realistic scenario and maximizing the learning due to the quality of the specimens. ${ }^{[13]}$

\section{Conclusion}

The portfolio of activities developed for teaching anatomy in a course that uses active teaching-learning methodology (PBL) was quite variable and contemplated important aspects involved in the whole teaching-learning process as: self-directed study, manual and communication skills and teamwork. In addition, students were guided to have a critical and reflexive position on the content who was contextualized to the integrated curriculum of the course. These activities should be evaluated and improved along the process, as well as the addition of new pedagogical strategies in order to facilitate comprehension. ${ }^{[14]}$ However, the use of these teaching-learning tools should always be contextualized based on the available structure and local reality to be better used.

\section{Conflict of Interest}

Authors declared no conflict of interest.

\section{Author Contributions}

MVJB: manuscript conceptualization, investigation, methodology and writing manuscript, editing and revising; AMSJB: literature reviewing, writing manuscript, proof reading; SGD: manuscript editing and revising.

\section{Financial Disclosure}

This research did not receive any specific grant from funding agencies in the public, commercial, or not-forprofit sectors.

\section{Funding}

There were no external funding bodies involved in this investigation. 


\section{References}

1. Toledo Junior ACC, Ibiapina CC, Lopes SCF, Rodrigues ACP, Soares SMS. Problems-based learning: a new reference for constructing the medical curriculum. Revista Medica de Minas Gerais 2008;18:123-31.

2. Mattos MP. Active methodologies assisting in learning the morphological and functional sciences in a clinical perspective: an experience report. Journal of Medical and Biological Sciences 2017;16:146-50.

3. Montes MAA, Souza CTV. Strategy for teaching and learning of human anatomy for medical students. Ciências \& Cognição 2010;15: 002-12.

4. Mourthé Filho A, Borges MAS, Figueiredo IPR, Villalobos MIOB, Taitson PF. Reflecting the teaching of human anatomy. Enfermagem Revista 2016;19:169-75.

5. Costa GBF, Costa GBF, Lins CCSA. The corpse in the teaching of human anatomy: a methodological and bioethics overview. Revista Brasileira de Educação Médica 2012;36:369-73.

6. Fornaziero CC, Gil CRR. New technologies applied to the teaching of human anatomy. Revista Brasileira de Educação Médica 2003;27:14146.

7. Crochemore MG, Marques AC. The discipline of human anatomy in the graduation course of physical education: considerations of graduates about its practice teaching relevance. Revista Thema 2017;14:828.

ORCID ID:

M. V. J. Barbosa 0000-0002-6699-7902; A. M. S. J. Barbosa 0000-0002-1858-3473;

S. G. Duarte 0000-0003-3866-8308
8. Cintra RB. Challenges of human anatomy teaching in medical schools. Revista Científica UMC 2017;2:1-16.

9. Pereira APC, Secorun AC, Rocha DP, Consoni VH. O uso de peças anatômicas criodesidratadas no ensino da anatomia. Revista Uningá 2006;10:105-11.

10. López FB, Sandoval MC, Giménez MA, Rosales VP. Assessment of anatomical models activity in the competence development in undergraduate students and their relationship to learning style, career and sex. Int J Morphol 2011;29:568-74.

11. Ferreira GI, Carreira LB, Botelho NM. International mobility in medical graduation: experience report. ABCS Health Science 2017;42:11519.

12. Guskuma EM, Dullius ASS, Godinho MSC, Costa MST, Terra FS. International academic mobility in nursing education: an experience report. Revista Brasileira de Enfermagem 2016;69:929-33.

13. Barbosa MVJ, Barbosa AMSJ, Duarte SG. Internationalization in teaching anatomy - an important step to start a reflexive-critical view on medical education. JSM Anatomy and Physiology 2020;5:1-4.

14. Goulart L, Remijo KM, Silva AA, Santos NGB, Merini LR, Brito LS, Pereira EM. Body painting as a methodological resource for the teaching of human anatomy for medical students of the Federal University of Amazonas, Brazil. Educación Física y Deportes 2015;209:1-6.

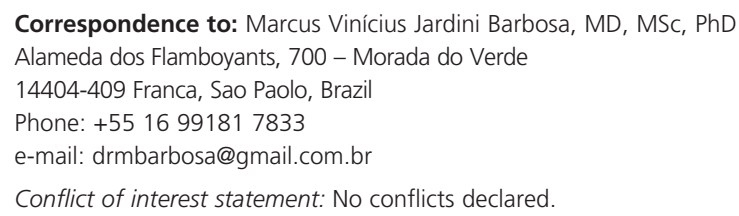

This is an open access article distributed under the terms of the Creative Commons Attribution-NonCommercial-NoDerivs 4.0 Unported (CC BY-NCND4.0) Licence (http://creativecommons.org/licenses/by-nc-nd/4.0/) which permits unrestricted noncommercial use, distribution, and reproduction in any medium, provided the original work is properly cited. How to cite this article: Barbosa MVJ, Barbosa AMSJ, Duarte SG. Pedagogical challenges in teaching anatomy on a problem-based learning curriculum. Anatomy 2020;14(2):117-122. 